\title{
Пути улучшения результатов лечения острой эмпиемы плевры
}

\author{
Е. Ю. Тронина, П. П. Шипулин, В. В. Байдан, В. Е. Севергин, Р. П. Никитенко
}

Одесская областная клиническая больница

\section{Ways of improvement of the treatment results for an acute pleural empyema}

\author{
E. Yu. Tronina, P. P. Shipulin, V. V. Baydan, V. E. Severgin, R. P. Nikitenko \\ Odessa Regional Clinical Hospital
}

\begin{abstract}
Реферат
Цель исследования. Анализ результатов лечения острой эмпиемы плевры (ОЭП) с использованием новых миниинвазивных технологий.

Материалы и методы. Представлен опыт выполнения видеоторакоскопических операций (ВТО) при ОЭП с использованием эндостаплеров и электросварочных инструментов, а также вакуум-терапии (ВТ). Как вариант закрытие плевро-легочных свищей (ПЛС) при ОЭП выполняли с помощьЮ метода радиочастотной абляции (РЧА).

Результаты. Все больные благополучно перенесли миниинвазивные вмешательства, средний срок стационарного лечения составил $(14,2 \pm 4,9)$ дня. Осложнения в виде нагноения ран и формирования остаточных полостей (ОП) возникли у 16 (20,3\%) больных.

Выводы. ВТО позволяют добиться хороших результатов лечения ОЭП и снизить частоту развития хронического процесса, особенно при условии соблюдения индивидуального подхода в лечении каждого пациента.

Ключевые слова: острая эмпиема плевры; видеоторакоскопические операции; вакуум-терапия.

Abstract

Objective. Analysis of the treatment results in an acute pleural empyema (APE) using new miniinvasive technologies.

Materials and methods. Experience of performance of videothoracoscopic operations (VTHO) in APE using endostaplers and electric welding tools, as well as vacuum-therapy, is presented. As a variant of treatment, the pleuro-pulmonary fistulas closure in APE was done, using method of radio-frequency ablation.

Results. All the patients have undergone miniinvasive interventions safely, average period of stationary treatment have constituted (14.2 \pm 4.9$)$ days. Complications with the wounds suppuration and the residual cavities formation have occurred in $16(20.3 \%)$ patients.

Conclusion. VTHO permits to achieve good results of the APE treatment and to lower the chronic process development rate, peculiarly while exploiting an individual approach for treatment of every patient.

Key words: acute pleural empyema; videothoracoscopic operations; vacuum-therapy.
\end{abstract}

Накопленный опыт применения ВТО в лечении ОЭП показал бесспорное их преимущество по сравнению с традиционными методиками [1 - 4]. В то же время остается проблемой лечение ОЭП, осложненной ПЛС и наличием ОП, что нередко приводит к развитию хронического воспалительного процесса и значительному увеличению длительности лечения больных [5]. Из сообщений о применении программируемых видеоторакоскопических санаций с вакуум-терапией (BT) невозможно сделать окончательный вывод об эффективности этого метода [6 - 8]. Мы представляем свой накопленный опыт применения миниинвазивных хирургических технологий в лечении ОЭП.

Цель исследования: анализ результатов лечения ОЭП и определение путей улучшения лечения данной патологии.

\section{Материалы и методы исследования}

В исследование вошли 79 больных с ОЭП, в лечении которых были применены новые миниинвазивные технологии. Возраст больных - от 16 до 91 года, мужчин было 56, женщин - 23. Постпневмоническая ОЭП выявлена у 67 (84,8\%) больных, туберкулезная - у 8 (10,1\%), на фоне абсцессов печени - у 2 (2,5\%), вследствие распада злокачественной опухоли - у 1 (1,3\%), посттравматическая - у 1 (1,3\%) больного.

У всех больных выявлен острый нагноительный процесс в плевральной полости со сроками заболевания до 1 мес. По результатам бактериологического исследования у 20 (25,3\%) больных отмечен рост Р. aeruginosa, у 7 (8,8\%) - Klebsiella pneumonia, y 4 (5,1\%) - Staphylococcus aureus, y $3(3,8 \%)$ - S. epidermidis, y $3(3,8 \%)$ - S. haemoliticus, y 4 (5,1\%) - E. cloacae, y 1 (1,3\%) - Acinetobacter, y 1 (1,3\%) - Serratia marcescens. У 11 (39,2\%) больных характер микрофлоры верифицировать не удалось. Микробные ассоциации отмечены у 5 (6,3\%) больных.

В объем обследования у всех больных входило полипозиционное рентгенологическое исследование и компьютерная томография органов грудной полости, фибробронхоскопия, бактериологическое и цитологическое исследование плеврального экссудата.

Показаниями к ВТО при ОЭП были: сохраняющаяся экссудация и прогрессирование гнойного процесса, наличие множественных осумкований жидкости, наличие ПЛС и ОП, неэффективность дренирования и консервативной терапии. 
К атипичным резекциям легкого при ОЭП прибегали, если возникала необходимость морфологического уточнения природы гнойного процесса, а также при наличии периферически расположенных участков деструкции легочной ткани с бронхиальными свищами, когда была возможность видеоторакоскопической резекции этого участка легкого.

Программируемые ВТО с коагуляцией ПЛС и ВТ с временной пломбировкой гнойной полости выполняли при наличии ограниченных ОП, не устраняемых обычным дренированием.

Методика ВТО при ОЭП существенно не отличалась от описанной нами ранее [9, 10]. У $37 \%$ больных был использован наркоз с выключением из акта дыхания оперируемого легкого, у 42\% - местная анестезия при сохраненном самостоятельном дыхании. При этом осуществляли местную анестезию зон введения торакопортов. Внутриплевральные манипуляции анестезии не требовали, за исключением случаев необходимости биопсии париетальной плевры. В данной ситуации под париетальную плевру, намеченную для биопсии, путем чрескожной пункции вводился анестетик. В объем ВТО обязательно включалось разобщение внутриплевральных перемычек с образованием единой полости, ранняя декортикация легкого с удалением фибринозных наложений и обязательное промывание плевральной полости.

Атипичные видеоторакоскопические резекции при ОЭП выполняли как с помощью эндостаплеров и механического шва, так и электросварочным методом. Техника подобных вмешательств детально освещена в предыдущих наших сообщениях [10, 11].

При наличии ПЛС и невозможности резецировать несущий их участок легочной паренхимы применяли РЧА ПЛС с помощью аппарата ЭХВЧ-150-«Фотек» и специальных электродов. РЧА проводили не только в зоне свищевого хода, но и в его окружности. РЧА осуществлялась автоматически с прекращением воздействия после необходимой его экспозиции.

Методика программированных видеоторакоскопических санаций (ПВТС) заключалась в выполнении миниторакотомного доступа (4 - 5 см) в проекции гнойной полости с последующим ее осмотром путем введения видеокамеры через выполненный доступ либо дополнительный торакопорт. После санации полости и коагуляции либо РЧА ПЛС ее туго тампонировали стерильной поролоновой губкой, смоделированной по размерам полости. Помимо установки поролонового обтуратора, остаточную полость дренировали двумя дренажами с целью создания вакуума и постоянной аспирации содержимого. Минидоступ ушивали только кожными швами.

При последующих ПВТС швы снимали для удаления обтуратора, повторной санации гнойной полости и дополнительной коагуляции ПЛС. При очищении полости и прекращении сброса воздуха ОП дренировали с ушиванием доступа. Все ВТО при ОЭП обязательно завершали дренированием плевральной полости с постоянной активной аспирацией содержимого.

\section{Результаты}

Применение указанных технологий в лечении ОЭП привело к выздоровлению 75 (94,9)\% больных, средний срок стационарного лечения составили $(14,2 \pm 4,9)$ дня. На значительное сокращение сроков стационарного лечения при использовании ВТО в лечении ОЭП указывают и другие авторы [2, 5, 7]. Летальных исходов в анализируемой группе не отмечено. Осложнения в виде нагноения ран, формирования ОП возникли у 27 (34,2\%) больных.

Всего различные виды атипичных резекций в ходе ВТО были выполнены у 25 (31,6\%) больных. Выполнять их можно с использованием местной анестезии, и не всегда требуется наркоз с выключением легкого из дыхания.

Необходимость верификации патологического процесса служила основным показанием к резекции участка легкого, что позволило у 4 больных установить туберкулезную и у 1 больного - раковую этиологию ОЭП. Атипичные эндоскопические резекции легкого при лечении ОЭП могут выполняться только по срочным показаниям и не должны значительно усложнять ход ВТО.

\section{Обсуждение}

К настоящему времени методика проведения ВТО при ОЭП достаточно хорошо разработана [1 - 5] и включает в себя обязательное разобщение внутриплевральных перемычек и слияние гнойных полостей в единую с ее последующей санацией под контролем видеокамеры, раннюю декортикацию легкого с адекватным дренированием плевральной полости. Все проведенные нами ВТО при ОЭП обязательно состояли из этих этапов. Их успешное проведение оказалось возможным при использовании местного обезболивания.

Быстрое расправление легкого с постоянной санацией единой гнойной полости, как правило, вело к купированию гнойного процесса с самостоятельным закрытием мелких ПЛС. Гораздо более сложные ситуации возникали при наличии обширных участков деструкции легкого с наличием множественных ПлС, при которых указанная методика была не всегда эффективна и у ряда больных приводила к формированию стойких остаточных полостей с тенденцией к переходу процесса в хронический. У больных острым воспалительным процессом и периферически расположенными ПЛС выполняли атипичную и краевую резекцию пораженного участка легкого. С этой целью применяли как механическую резекцию с помощью эндостаплера, так и электросварочную либо их комбинацию. Методики этих вмешательств подробно изложены в нашем сообщении [9].

Рецидив ОЭП обычно обусловлен наличием ПЛС, не позволяющих достигнуть своевременного расправления легкого. Согласно рандомизированным исследованиям M. Scarci и соавторов именно ПлС оказывают основное влияние на результаты лечения ОЭП и требуют индивидуальной лечебной тактики в каждом случае [5]. Все рецидивы ОЭП были обусловлены именно этим фактором. Различные виды коагуляции и сварки свищей в ходе проведения ВТО были использованы у 15 (19\%) 
больных. Эффективным этот метод оказался у 9 больных, у 6 - наступил рецидив ПлС, из-за чего значительно удлинились сроки стационарного лечения.

Собственный клинический опыт показал әффективность торакоскопической коагуляции ПЛС при наличии хорошо сформированного свищевого хода и отсутствии деструкции окружающей легочной ткани. Ограниченный опыт использования этой методики пока не позволяет достоверно сравнить результаты электрокоагуляции и РЧА ПЛС, однако, применяя последнюю методику, сварке подвергали не только свищевой ход, но и окружающую паренхиму легкого, что приводило к стойкому прекращению сброса воздуха.

Неэффективной РЧА ПЛС оказалась у 6 больных, что мешало расправлению легкого. Причинами этого являлось наличие множественных ПЛС и зон деструкции легочной ткани.

По нашему мнению, коагуляция либо РЧА очень сложна и недостаточно эффективна при наличии множественных ПЛС с участками деструкции легочной ткани. Это обстоятельство послужило поводом к разработке сочетанного применения этого метода с ПВТС и ВТ.

Хотя об эффективности ВТ гнойных полостей сообщает ряд хирургов [6 - 8], этот метод остается недостаточно разработанным и распространенным в клинической практике. Остается неясной частота ПВТС и смены губки в остаточной полости. Отдельные авторы рекомендуют делать это каждые 2 - 5 дней [8].

Сообщений об использовании метода ПВТС с ВТ немного [1, 6], но во всех отмечаются высокая эффективность метода и сокращение сроков лечения ОЭП, хотя сам метод достаточно трудоемок.

Собственный опыт применения ПВТС с ВТ в лечении 10 больных с ОЭП невелик, что не позволяет сделать окончательные выводы. Однако эффективность этой методики наглядно подтверждена результатами лечения ОЭП у одного больного преклонного возраста, имеющего тяжелую сопутствующую патологию, что подтверждено данными компьютерных томограмм. Остаются неясными сроки нахождения поролоновых обтураторов в гнойной полости, частота их замены и количество ПВТС. Несомненно, необходимым условием проведения ВТ является наличие систем постоянной активной аспирации содержимого плевральной полости.

\section{Выводы}

1. Выполнение ВТО при ОЭП позволяет значительно улучшить результаты лечения больных с сокращением сроков пребывания их в стационаре и снизить частоту развития хронического процесса.

2. Наличие ПЛС требует индивидуального подхода в лечении больных с использованием различных методик закрытия свищей, включая ВТ.

3. ПВТС с ВТ - новый перспективный метод лечения осложненных форм ОЭП.

4. Применение атипичных резекций при ВТО в лечении ОЭП имеет достаточно ограниченные показания и значительно повышает себестоимость вмешательства.

\section{References}

1. Jasnogorodskij OO, Shulutko AM, Saakjan NA. Videotorakoskopija v kompleksnom lechenii nespecificheskoj jempiemy plevry. Endoskopich Hir. 2001;6:46-8. [In Russian].

2. Casali C, Storelli ES, Di Prima E, Morandi U. Long-term functional results after surgical treatment of parapneumonic thoracic empyema. Interact Cardiovasc Thorac Surg. 2009 Apr 14;9(1):74-8. doi: 10.1510/ icvts.2009.203190.

3. Chung JH, Lee SH, Kim KT, Jung JS, Son HS, Sun K. Optimal timing of thoracoscopic drainage and decortication for empyema. Ann Thorac Surg. 2014 Oct 8;97(1):224-9. doi: 10.1016/j.athoracsur.2013.08.039.

4. Waller DA, Rengarajan A. Thoracoscopic decortication: a role for video-assisted surgery in chronic postpneumonic pleural empyema. Ann Thorac Surg. 2001 Jan 19;71(6):1813-6. doi: 10.1016/S00034975(01)02471-7.

5. Scarci M, Abah U, Solli P, Page A, Waller D, van Schil P, et al. EACTS expert consensus statement for surgical management of pleural empyema. Eur J Cardiothorac. Surg. 2015 Aug 7;48(5):642-53. doi: 10.1093/ejcts/ezv272.

6. Barskij BG, Zhestkov KG, Kosachenko VM, Bykov AN, Kuznecova OA. Odnoportovye torakoskopicheskie programmirovannye sanacii i minitorakostomija s vakuum-terapiej v lechenii jempiemy plevry. Vysokoteh Med. 2015 Sent;3:30-9. [In Russian].

7. Groetzner J, Holzer M, Stockhausen D, Tchashin I, Altmayer M, Graba $\mathrm{M}$, et al. Intrathoracic application of vacuum wound therapy following thoracic surgery. Thorac Cardiovasc Surg. 2009 Sep 30;57(7):417-20. doi: $10.1055 / \mathrm{s}-0029-1185907$

8. Haghshenasskashani A, Rahnavardi M, Yan TD, McCaughan BC. Intrathoracic application of a vacuum-assisted closure device in managing pleural space infection after lung resection: is it an option? Interact Cardiovasc. Thorac Surg. 2011 May 20;13(2):168-74. doi: 10.1510/ icvts.2011.267286.

9. Tronina EYu, Shipulin PP, Bajdan VI, Severgin VE, Bajdan VV, Ageev SV, i dr. Vozmozhnosti sovremennyh tehnologij v lechenii jempiemy plevry. Klinichna khirurhiia. 2016;3: 46-8. [In Russian].

10. Shipulin PP, Kiriljuk AA, Tronina EJu, Bajdan VV, Severgin VE, Bajdan VI, i dr. Videotorakoskopicheskaja rezekcija legkih $\mathrm{s}$ ispolzovaniem jelektrosvarochnyh tehnologij. Klinichna khirurhiia. 2017;6:42-4. [In Russian].

11. Grubnik VV, Kiriljuk AA, Shipulin PP, Bajdan VV, Severgin VE, Tronina EJu. i dr. Videotorakoskopicheskaja atipichnaja rezekcija legkogo s ispolzovaniem razlichnyh hirurgicheskih tehnologij. Klinichna khirurhiia. 2015;3:17-9. [In Russian]. 